\title{
Microwave-Assisted Diels-Alder Approach to 4-Substituted Indoles
}

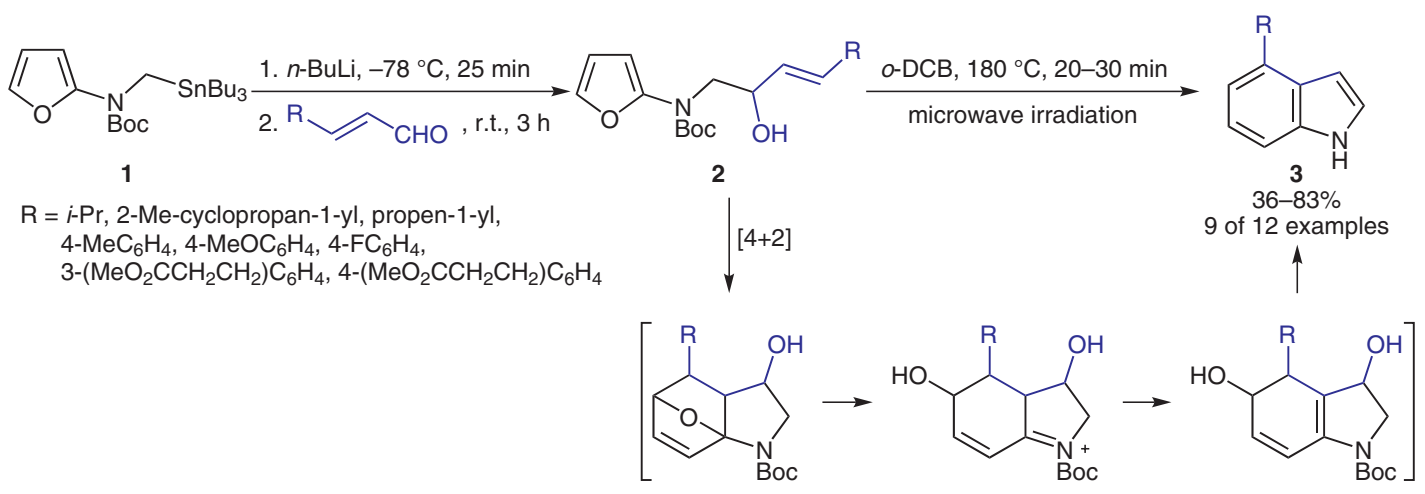

Other examples:<smiles>c1cc2c3c(c[nH]c3c1)CCC2</smiles><smiles></smiles><smiles>c1cc(-c2cccc3[nH]ccc23)cc(-c2cccc3[nH]ccc23)c1</smiles>

$\mathrm{R}=\mathrm{Boc} / \mathrm{H}(7: 4)$

Significance: Wipf and co-workers report a versatile synthesis of 4-substituted indoles 3 initiated by addition of an $\alpha$-lithiated alkylaminofuran to carbonyl compounds followed by microwaveaccelerated intramolecular Diels-Alder (IMDA) reaction and aromatization. The starting stannane $\mathbf{1}$ is easily prepared by alkylation of Boc-protected 2-aminofuran. Transmetalation of stannane $\mathbf{1}$ with $n$-BuLi gives a lithium species which is trapped with an aldehyde to give the expected allylic alcohols $\mathbf{2}$. Heating furans $\mathbf{2}$ at reflux in toluene leads to gradual decomposition; however, the IMDA reaction proceeds smoothly with concomitant Boc deprotection at high temperature in o-DCB under microwave irradiation, presumably via the mechanism shown. This method exhibits moderate functional group tolerance, with aromatic groups clearly favored over alkyl groups. One example of the preparation of a 3,4-disubstituted indole is also presented.
Comment: Indoles are ubiquitous in nature and are present in many pharmaceutical agents. Many methods exist for the synthesis of indoles and saturated indole derivatives, from classical reactions such as the Fischer synthesis to more recent transition-metal-catalyzed reactions (see Book below). The current method represents a rapid and convenient synthesis of monosubstituted indoles that complements existing transition-metalmediated methodologies. Performing the key cyclization step in a pressurized reaction vessel under microwave irradiation may limit the utility of this methodology to small scale applications.

Book: J. A. Joule, In Science of Synthesis, Vol. 10; E. J. Thomas, Ed.; Thieme: Stuttgart, 2000, 361-593. 